shall these deviations be viewed? Is the foliage of the sassafras passing through a period in which different forms of leaves are being tried to see which is best adapted to the surroundings? It may be that there is a tendency from the simple towards the more complex; and fig. 3 shows the form which may be finally adopted. This is a subject about which even the philosophic botanists know but little; but, when one finds these deviations from the common form, he cannot help wondering after what end the plant bearing them is striving. ByRoN D. HALSTED.

\section{The thickness of the ice in New England in glacial times.}

In the issue of ScInNCE for Sept. 28, Professor Wright corrects a reported statement of what he said about the depth of ice over New England, changing 600 feet to 6,000 feet, and giving as proof the wellknown fact that Mounts Mansfield and Washington show ice-action to a height above sea-level of between five and six thousand feet.

It seems to me that the depth 600 feet must be more nearly correct than 6,000 feet. The ice-sheet over New England must have had a thickness equal to the height of these mountain peaks above the level of the contiguous valleys. From the nature of the case we cannot well prove a greater thickness, though from theoretical considerations we may believe the ice to have been much thicker. 4,370 feet, the approximate difference between the top of Mount Washington and the Crawford House, must cover the greatest differences in elevation between neighboring valleys and mountains. The average thickness of the ice-sheet must have been much less (from this proof), possibly not more than 1,000 feet. This thickness would accord with what is believed to be the thickness of the ice to the north-westward.

The glacial striae and drift-bowlders upon Mount Washington at an elevation of 6,000 feet do not necessarily lead to the supposition that the upper ice-surface had that level in northern New England, and a greater elevation to the north-westward; for local accumulations of snow and consequent ice must have existed about the summits of the White, Green, and Adirondack Mountains, as in Switzerland and in Greenland at the present time, and have constituted the source of much of the ice which spread southward over southern New England and New York.

Eureka, Kan., Nov. 7.

L. C. Wooster.

\section{Museum of the Indiana university.}

In the account of the burning of the museum building of the Indiana university, given in ScIENCE for July 27, are one or two errors which need correction.

The Owen collection of minerals and fossils was not entirely destroyed. Eight large cases, including the great majority of the typical specimens of David Dale Owen, were saved. The very perfect skeleton of Megalonyx Jeffersoni was also saved.

No specimens belonging to Yale college or to Cornell university were in the museum at the time of the fire. About two thirds of the very large collection made by Professor Gilbert on the Pacific coasts of Mexico and Central America were destroyed; the remaining third having been returned to the U.S. national museum, to which institution it belonged.

A new fire-proof museum building is to be erected at once, and the restoration of the collections lost is rapidly progressing.

Bloomington, Ind.
THE FISH-COMMISSION BULLETIN.

Bulletin of the U.S. Fish-Commission, vol. ii., for 1882. [Edited by Charles W. Smiley, A.M.] Washington, Government, 1883. 467 p., illustr. $8^{\circ}$.

IN looking over the pages of this book, we find several papers of marked scientific value, written by eminent specialists in biology and fish-culture, - articles which of themselves are sufficient to give this document a prominent place upon the book-shelves of naturalists, and to render it a valuable book of reference, especially to embryologists and fish-culturists.

The articles written by J. A. Ryder deserve prominent notice; for not only do they have an important bearing upon the subject of embryology, but they also show the importance of scientific treatment in hatching and maturing fish-eggs. 'The two most important papers by this author are, $1^{\circ}$, 'The absorption of the yelk in the embryo shad; $2^{\circ}$, Microscopic sexual characteristics of the Arnerican, Portuguese, and common edible oyster of Kurope compared. Several smaller papers by the same author have especial bearing upon the successful hatching and rearing of the food-fishes of the Potomac.

The papers upon the distribution and specific character of fishes, with descriptions of new species, will be of special interest to systematic ichthyologists. A large part of the book is composed of letters of greater or less importance, written to the commissioner, mainly relating to the movements of fish in certain districts. We are of the opinion that a great many of these letters might have been left out entirely, without any serious loss to science. They might at least have been judiciously cut down, and published together as a series of notes; thus giving the important points, and omitting the great preponderance of useless words and sentences which one so frequently finds in these letters. The last article in the book is entitled, "A geographical catalogue of persons who have stated that they are interested in fish-culture," by C. W. Smiley.

Sandwiched between these various papers, we find one, which, in our estimation, is grossly unfit for a scientific publication of such a high standard. The title of this article is 'Life in the sea,' by J. B. Martens. It is a translation from the Dutch; and the author is teacher of natural sciences at the seminary of St. Nikolas, Belgium. From beginning to end, it is an absurd misrepresentation of facts, and deserves the severest condemnation. For instance: we find in the introductory paragraph the statement that "life in the sea 